at least has not explicitly and consistently included important epistemological commitments. He refers to the Vienna Circle as moderns and cites their abhorrence of metaphysics, for example, but does not go on to explore the epistemological implication. Nor does he examine the role of changing and alternative sets of epistemological values for the Americans, who often adopted a pragmatic research programme because in that way they could get something that they could accept as reliable knowledge. Similarly, for some of the Germans epistemology was of central importance, but not for others. This too cries out for more study.

Finally, Harwood only touches on the exciting question of why researchers did not take up certain problems, approaches or theories. Often scientists make choices because they are attracted to a particular research programme; but perhaps they are constrained by their basic commitments to other values, their social background or their institutional setting. Harwood criticizes Ludwik Fleck and Gerald Holton for saying that a style or themata can "guide" scientists' work because "ideas of themselves do not coerce". Yet a deep commitment to ideas - however instilled - can coerce. Understanding where, how and why the guiding or coercing occurs can help us to understand not just that styles of scientific thought exist but how they influence scientific development.

Harwood has provided a wonderful stimulus to further thinking about the development of genetics. His book should provoke exciting debates and important insights, even if new work undercuts some of his own suggestions. $\square$

Jane Maienschein is in the Departments of Philosophy and Zoology, Arizona State University, Tempe, Arizona 85287-2004, USA.

\section{Ancient oceans}

\section{E. Irving}

Paleomagnetism of the Atlantic, Tethys and lapetus Oceans. By Rob Van der Voo. Cambridge University Press: 1993. Pp. 411. £60, \$89.95.

RоB Van der Voo has devoted most of his life to the study of the palaeomagnetism of Palaeozoic rocks (590-248 million years old). From such studies, one may calculate the movements of the continents that have constrained the shape and distribution of oceans. Here he reviews the results as they relate to the evolution of the Palaeozoic Iapetus, the Late Palaeozoic to Early Mesozoic Tethys, and the Mesozoic and Cenozoic Atlantic Oceans.
A large obstacle in such studies is widespread remagnetization. In the Late Palaeozoic there was a global tectonic event that resulted in the final assemblage of Pangaea. Rocks were deformed, buried and flooded with basinal fluids to produce new magnetic minerals and stable magnetization. Older, more consolidated Precambrian rocks were little affected, but many Palaeozoic deposits were partially or completely remagnetized. Evidence for Late Palaeozoic remagnetization was discovered in the mid-1960s, but it was not until the early 1980s that its global nature was accepted. Meanwhile, workers had been fooled by this unwelcome phenomenon, mistaking younger for older magnetizations. Through all these vicissitudes, Van der Voo and others in the community have persisted; it is to their credit that palaeomagnetism is now as indispensable in the study of the tectonics of the Palaeozoic as it is in that of later eras. This book is a monument to their efforts. All tectonicists should read it.

The book's leitmotiv is the diagram of variation in declination and palaeolatitude. There are dozens of them. They make clear the general picture, but the errors in the measurements are not given: that is, errors critical to the estimation of drift rates and of the times of convergence and amalgamation of moving crustal blocks. Observed values are compared with those expected from neighbouring crustal blocks, and differences are interpreted as relative rotation about local vertical axes and relative palaeolatitudinal displacement. Calculations of this relative rotation and displacement and their errors are not generally made, and procedures for calculating them are not explained.

A second prominent subject is palaeomagnetic tests of continental reconstructions. Van der Voo provides a masterly demonstration of the superiority, over others, of Sir Edward Bullard et al.'s fit of the northern continents. His discussion of the reconstructions of the Gondwana continents is serviceable, but less mature because of the sparsity of data for the Southern Hemisphere (although he gives up too easily on Pangaea B). Future analyses will no doubt limit further options for mappers of the Palaeozoic Earth, and the book admirably sets the stage for their work.

There are many charming asides where the author reveals his habits of thought, one of which is to complain regularly about the frequent unsuitability of data for the task he has in mind. He forgets, perhaps, that some were obtained with different objectives. Data, good or bad, suitable or unsuitable, have an unfortunate habit of becoming out of date, and what really counts in the long run is the quality and durability of ideas developed from them. Far better to rejoice that, from a standing start in the late 1940s, palaeomagnetists have contributed many fundamental ideas to Earth science, contributions to which this book bears undeniable witness.

E. Inving is emeritus scientist in the Pacific Geoscience Center, Geological Survey of Canada, PO Box 6000, Sidney, British Columbia, Canada V8L 4B2.

\section{Overstuffed}

\section{Jeremy J. D. Greenwood}

Manual of Ornithology: Avlan Structure and Function. By Noble S. Proctor and Patrick J. Lynch. Yale University Press: 1993. Pp. 340. £30, \$45.

PROCTOR and Lynch believe that there is a need for a laboratory manual "to collect under one cover the visual references necessary for an undergraduate laboratory course in ornithology". Given the limited number of illustrations in textbooks, there may well be such a need. If so, the illustrations in this book fill it. Not only do they portray avian morphology in detail but they do so clearly, making reference to specimens straightforward.

Unfortunately, the book contains no dissection instructions, although it describes how to prepare study skins, surely a much less important skill than basic dissection. One of the clearest instructions for preparing a study skin is: 'Do not overstuff the specimen'. It is advice that the authors would have done well to follow. For example, a chapter on field techniques fits uncomfortably in what is otherwise strictly a laboratory manual. Another element of overstuffing is that there is too much repetition in both the text and the illustrations - eight pictures to show general topography, for example, with three more for the details of the wing and four for the head. But the main way in which the book has been extended is in the background and supporting material. The authors admit that they found it difficult to walk the tightrope between textbook and reference manual. They have chosen to include much material extending beyond the basic morphology appropriate to a laboratory manual, in an attempt to relate the morphology to the life and natural history of birds. Unfortunately, this material is too brief and too idiosyncratic to be any substitute for an ornithology textbook, yet it is voluminous enough to get in the way of using the book as a laboratory manual. There may be a need for a laboratory manual in ornithology, but this does not meet it in a useful way.

Jeremy J. D. Greenwood is in the British Trust for Ornithology, The Nunnery, Thetford, Norfolk IP24 2PU, UK. 